\title{
Carbon Dioxide Storage and Sequestration in Unconventional Shale Reservoirs
}

\author{
S. Sina Hosseini Boosari ${ }^{1}$, Umut Aybar ${ }^{2}$, Mohammad O. Eshkalak ${ }^{2}$ \\ ${ }^{1}$ West Virginia University, Morgantown, WV, USA \\ ${ }^{2}$ Petroleum and Geosystems Engineering Department, The University of Texas at Austin, Austin, TX, USA \\ Email: moeshkalak@gmail.com
}

Received 16 February 2015; accepted 14 March 2015; published 20 March 2015

Copyright (C) 2015 by authors and Scientific Research Publishing Inc.

This work is licensed under the Creative Commons Attribution International License (CC BY).

http://creativecommons.org/licenses/by/4.0/

c) (i)

Open Access

\begin{abstract}
Carbon Dioxide $\left(\mathrm{CO}_{2}\right)$ storage and sequestration in unconventional shale resources has been attracting interest since last couple of years due to the very unique characteristics of such formations have made them a feasible option for this object. Shale formations are found all around the world and the conventional assets are easily accessible, and also the huge move of operators toward developing unconventional reservoirs during past years leaves many of such formations ready for sequestering $\mathrm{CO}_{2}$. Today, the use of long horizontal wells that are drilled on a pad has the lowest amount of environmental footprint in which for storage and sequestration purpose also provides much more underground pore spaces available for $\mathrm{CO}_{2}$. In this paper we study the state of the art of the technology of $\mathrm{CO}_{2}$ storage and sequestration and provide different and fresh look for its complex phenomena from a mathematical modeling point of view. Moreover, we hope this study provides valuable insights into the use of depleted shale gas reservoirs for carbon sequestration, which as a result, a cleaner atmosphere will be achieved for the life of our next generations. Also, we present that the depleted shale gas reservoirs are very adequate for this purpose as they already have much of the infrastructure required to perform $\mathrm{CO}_{2}$ injection available in sites.
\end{abstract}

\section{Keywords}

Carbon Dioxide Sequestration, Shale Reservoirs, Modeling and Simulation, Clean Environment

\section{Introduction}

Geologic formations and abundant reservoirs have attracted much attention within the engineering community for the purpose of reducing carbon dioxide of the atmosphere through storing and sequestration process in recent years. Worldwide energy demand is supported by the significant role of conventional and unconventional resources of oil and gas. This huge dependency has resulted in critical environmental issues such as increased $\mathrm{CO}_{2}$ 
emission known as the greenhouse gas, and for the purpose of having a clean atmosphere for next generations, $\mathrm{CO}_{2}$ storage and sequestration has gotten a common procedure for this purpose. During the last decade, energy equations are changed due to the advances obtained in drilling and fracturing of unconventional reservoirs both in the US and worldwide. The main simple difference between conventional and unconventional resources is the fact that unconventional are scattered all around the world but conventional exist just in some parts of the world. This strongly means that since unconventional are everywhere on the map then the $\mathrm{CO}_{2}$ sequestration in such reservoirs are very reasonable and economically feasible [1] [2].

Shale gas is mostly methane that is trapped within the shale formations. Shale is located thousands of feet below earth surface. Gas-productive shale formations in the continental US are of thermogenic or biogenic origin and are found in Paleozoic and Mesozoic rocks. Shale is a fine-grained sedimentary rock that, when deposited as mud, can collect organic matter. When the organic matter decays over time, petroleum and natural gas products are formed within the rock's pores. Shales typically hold dry gas, but some formations produce liquid products as well. Conventional gas reservoirs form from the migration of natural gas from an organic-rich source into permeable reservoir rock. Unconventional gas-rich shales, however, generally function as both the source and reservoir for natural gas. Shales have low permeability, which means that trapped gas cannot move easily within the rock. Because of this, a technique called hydraulic fracturing is employed to produce the natural gas. This unique characteristic benefits the sequestration of $\mathrm{CO}_{2}$. Hydraulic fracturing cracks the shale rock through the injection of water, sand, and chemicals at high pressure.

Underground storage and sequestration of carbon dioxide involves the process of injecting highly pressurized $\mathrm{CO}_{2}$ into the formations considering the capability of the rock to permanently keep it from leaking toward the earth surface. There are five applicable options for safely sequestering the carbon dioxide into the geologic formations. Saline formations, basalts, un-mineable coal seams, conventional oil and gas reservoirs and depleted unconventional shale resources are technically studied during the course of this paper. As of now, considering the advances gained through last couple of years in carbon management, scientists have proposed the following statements: 1) estimating $\mathrm{CO}_{2}$ storage capacity +/- 30 percent in geologic formations; 2) ensuring 99 percent storage permanence; 3) improving efficiency of storage operations; and 4) developing Best Practices Manuals [3] [4]. These technologies will lead to future $\mathrm{CO}_{2}$ management for coal-based electric power generating facilities and other industrial $\mathrm{CO}_{2}$ emitters by enabling the storage and utilization of $\mathrm{CO}_{2}$ in all storage types.

In the U.S., Nuttall et al. (2005) estimated the $\mathrm{CO}_{2}$ sequestration capacity in the organic-rich Devonian black shales in the Big Sandy gas field of Eastern Kentucky to be about $6.8 \mathrm{Gt}$. To illustrate the importance of shale formations for $\mathrm{CO}_{2}$ storage in Europe, the Dutch resource of shale gas own an estimation of between 48,000 and $230,000 \mathrm{Bcm}$. If one assumes that technology can be developed to store $1 \mathrm{~m}^{3}$ of $\mathrm{CO}_{2}$ for $1 \mathrm{~m}^{3}$ of $\mathrm{CH}_{4}$ produced, and that only one percent of the resource can be recovered, a substantial $480-2300 \mathrm{Bcm}$ of $\mathrm{CO}_{2}$, corresponding to 0.9 to 4.35 Gton $\mathrm{CO}_{2}$, could be stored. In this paper we further analyze the developments, advances and issues related to methods that are in practice and authors will provide alternative technologies that are given a fresh look toward the classical research.

\section{Shale Gas Resources in the U.S. and Worldwide}

In 2000 shale gas provided only 1\% of U.S. natural gas production; by 2010 it is over 20\% and the U.S. government's Energy Information Administration predicts that by 2035, 48.9\% of the United States' natural gas supply will come from shale gas. These trends obviously demonstrate that we can expect that shale gas will greatly expand worldwide energy supply. Further, China is estimated to have the world's largest shale gas reserves. Some researches show that shale gas production in the USA and Canada could help Europe to be less dependent to Russian and Persian Gulf countries. Figure 1 shows that unconventional resources (Shale Gas, Tight Gas, Coalbed Methane) containing hydrocarbon are almost all over the world. The most common form of unconventional natural gas is shale gas. In this study, the main focus will be on storage and sequestration in shale gas.

\section{Shale Reservoirs Modeling and Simulation}

Reservoir simulation and modeling of unconventional resources have been given much more attention over the past years. Many numerical and analytical models have been developed and extensive reservoir studies have been conducted. Commercial reservoir simulators are also improved to handle and capture fluid flow behavior 


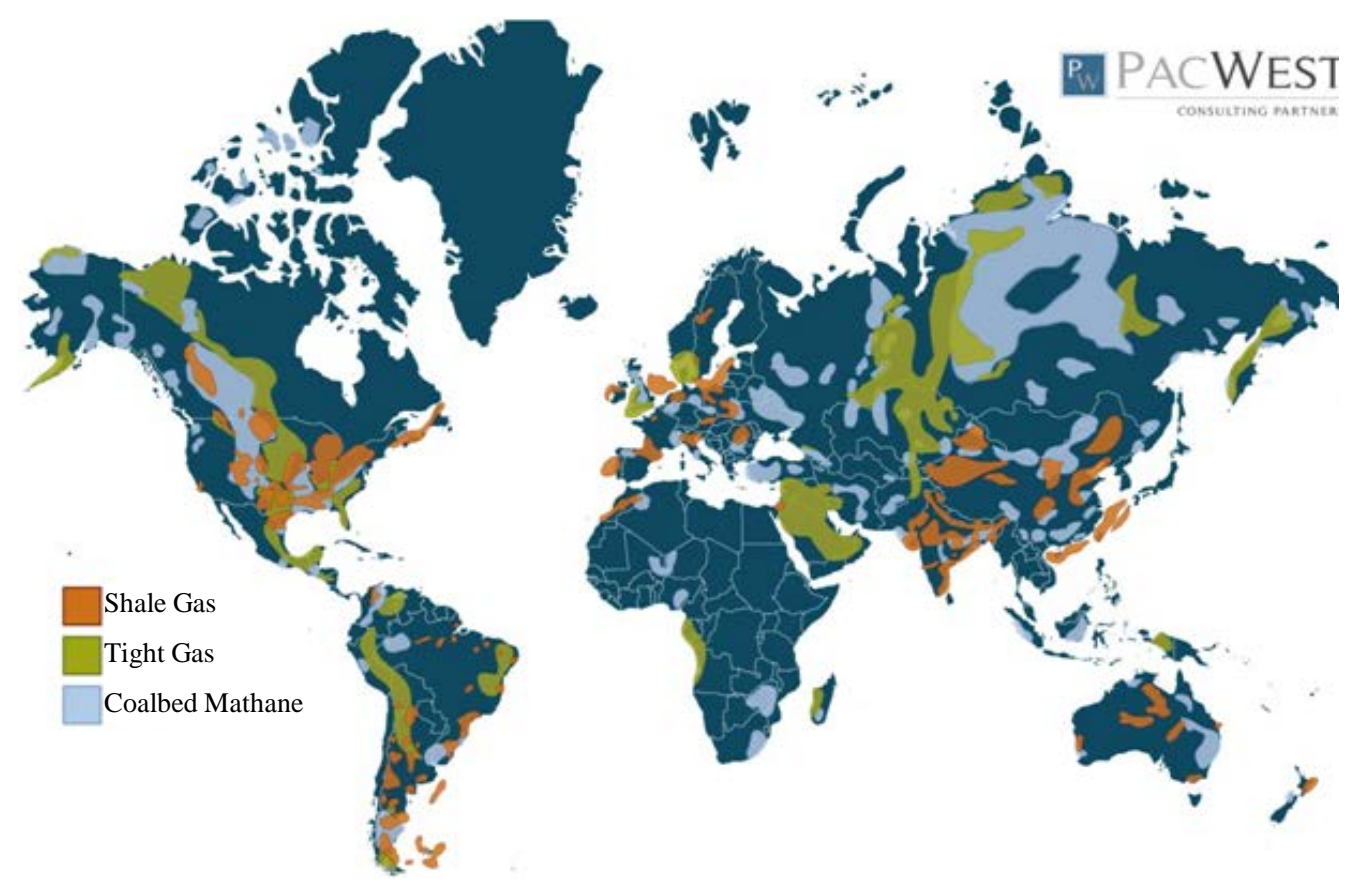

Figure 1. Worldwide shale gas resources.

and natural gas production from unconventional assets, such as shale. However, developing an unconventional reservoir model that accounts for all pressure dependent phenomena and integrates all physics incorporated in gas flow for tight formations is still a challenging target for the petroleum industry. Among analytical and semianalytical methods, works done by [5] [6] have provided comprehensive progress in the modeling of shale gas reservoirs. Many authors, such as [7] [8], have used numerical simulation techniques in order to model different aspects of unconventional shale reservoirs.

Analytical reservoir models are widely employed because of their relative simplicity compared to numerical approaches. The aim of analytical solutions is to provide a simple solution which covers the fundamental physics of the phenomenon. In order to accomplish these goals, the analytical solution must have some simplifying assumptions. Having constant and/or homogeneous rock and fluid properties (density, compressibility, permeability, and viscosity) are the common assumptions for analytical solutions. The purpose of these assumptions is to linearize the partial differential equations arising from modeling of fluid flow in a reservoir; in our case, the diffusion equation. There are two methods in the literature customarily preferred for analytical fluid flow solutions: one is proposed by [9] [10], which has solution in time domain; while the other techniques are introduced by [11] and use Laplace transformation for solutions. Following these two solution techniques, researchers have proposed analytical solutions for hydraulically fractured unconventional reservoirs [12] [13]. Analytical reservoir models are applicable for quite accurate, simple and robust simulations to evaluate production performances of hydraulically fractured unconventional reservoirs.

Eshkalak et al. investigated the geo-mechanical properties of Marcellus shale. They generated a common source for securing these rock mechanical properties, geomechanical well logs, and studied various characteristics, such as minimum horizontal stress, young, bulk shear modulus, as well as poison's ratio that play an important role in defining the stress profiles of an unconventional reservoir. Moreover, having an access to rock geomechanical properties will enhance the understanding of the parameters, such as conductivity and pressure dependency of permeability [14]-[17].

In Figure 2, the natural gas production for past years and projections for following years are given. The shale gas is the only form of natural gas whose production amount is increasing. All other types of natural gas are either decreasing or remaining constant. It can be easily said that in the future the USA and world natural gas production is the shale gas, the $\mathrm{Y}$ axis is trillion cubic feet [1].

Generally, two-phase fluid flow of water and gas in a dual-permeability model is considered in constructing the geologic model of shale gas reservoirs. The dual-permeability model considers the intercommunication be- 


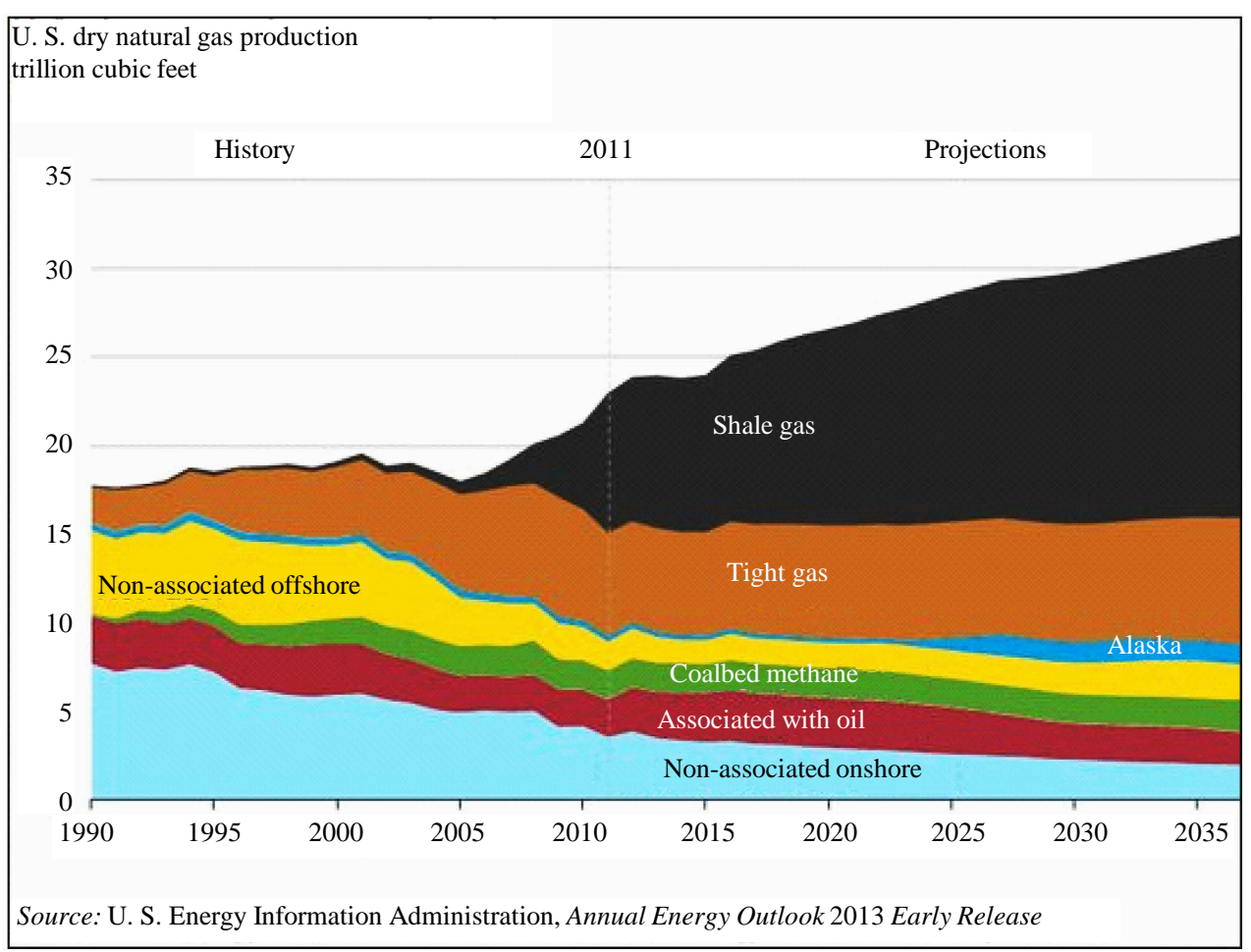

Figure 2. Natural gas production outlook.

tween the inter-granular void spaces in contrast to the dual-porosity model. Also, this model considers flow in two domains including the matrix and fracture. This model allows the transfer of both gas and water between the matrix and fracture domains, gas velocity in the matrix and fracture domains is calculated with the Equations (1) and (2):

$$
\begin{aligned}
& v_{g}^{m}=-\left(\frac{K_{g}^{m}}{\mu_{g}} \nabla P_{g}+\frac{D_{g}^{m}}{C_{g}^{m}} \nabla C_{g}^{m}\right) \\
& v_{g}^{f}=-\left(\frac{K_{g}^{f}}{\mu_{g}} \nabla P_{g}+\frac{D_{g}^{f}}{C_{g}^{f}} \nabla C_{g}^{f}\right)
\end{aligned}
$$

where $v_{g}$ is gas velocity, $K_{g}$ is gas permeability, $D_{g}$ is gas diffusivity, $P_{g}$ is gas pressure, $C_{g}$ is gas concentration, and $\mu_{g}$ is gas viscosity. Subscripts $m$ and $f$ represent matrix and fracture domains. Velocity of the water flowing in matrix and fracture are determined with Equations (3) and (4), respectively:

$$
\begin{aligned}
& v_{w}^{m}=-\left(\frac{K_{w}^{m}}{\mu_{w}} \nabla P_{w}^{m}\right) \\
& v_{w}^{f}=-\left(\frac{K_{w}^{f}}{\mu_{w}} \nabla P_{w}^{f}\right)
\end{aligned}
$$

where, $v_{w}$ is water velocity, $K_{w}$ is water permeability, $P_{w}$ is water pressure, and $\mu_{w}$ is water viscosity.

\subsection{Flow in Matrix}

The equations of gas transport thus are simplified for matrix domain as shown in Equation (5):

$$
\frac{\partial}{\partial t}\left(\frac{C_{g}^{m} P_{g}^{m}}{Z}\right)=\nabla\left(\frac{P_{g}^{m}}{Z} \frac{K_{g}^{m}}{\mu_{g}} \nabla P_{g}^{m}+D_{g}^{m} \nabla \frac{P_{g}^{m}}{Z}+\frac{D_{g}^{m}}{C_{g}^{m}} \frac{P_{g}^{m}}{Z} \nabla C_{g}^{m}\right)-\frac{R T}{M}\left(q_{w}^{m f}+q_{w}^{m}\right)
$$


where $Z$ is the gas compressibility factor, $R$ is the gas constant, $T$ is temperature, $M$ is gas molecular weight, and $q_{g}$ is gas mass flow rate per unit matrix-block volume. Subscript $m$ and $f$ represent the exchange between matrix and fracture. For the water phase, the same equation is shown in Equation (6):

$$
\frac{\partial}{\partial t}\left(\frac{\varnothing_{m} s_{w}^{m}}{B_{w}}\right)=\nabla\left(\frac{K_{w}^{m}}{B_{w} \mu_{w}} \nabla P_{w}^{m}\right)-\frac{R T}{M}\left(q_{w}^{m f}+q_{w}^{m}\right)
$$

where $\varnothing_{m}$ is matrix porosity, $s_{w}$ is water saturation, and $B_{w}$ is water compressibility factor.

\subsection{Flow in Fracture}

After some manipulation and simplifications, the gas flow governing equation in fracture becomes as the following Equation (7):

$$
\frac{\partial}{\partial t}\left(\frac{C_{g}^{f} P_{g}^{f}}{Z}\right)=\nabla\left(\frac{P_{g}^{f}}{Z} \frac{K_{g}^{f}}{\mu_{g}} \nabla P_{g}^{f}+D_{g}^{f} \nabla \frac{P_{g}^{f}}{Z}+\frac{D_{g}^{f}}{C_{g}^{m}} \frac{P_{g}^{f}}{Z} \nabla C_{g}^{f}\right)+\frac{R T}{M}\left(q_{w}^{m f}-q_{w}^{m}\right)
$$

For the water phase, Equation (8) represents the related formula.

$$
\frac{\partial}{\partial t}\left(\frac{\varnothing_{f} s_{w}^{f}}{B_{w}}\right)=\nabla\left(\frac{K_{w}^{f}}{B_{w} \mu_{w}} \nabla P_{w}^{f}\right)+\frac{R T}{M}\left(q_{w}^{m f}-q_{w}^{m}\right)
$$

Equations (9) to (12) represent the auxiliary relations used in the solution method.

$$
\begin{gathered}
C_{g}^{m}=\varnothing_{f} s_{w}^{m} \\
C_{g}^{f}=\varnothing_{f} s_{w}^{f} \\
s_{g}^{m}+s_{w}^{m}=1 \\
s_{g}^{f}+s_{w}^{f}=1
\end{gathered}
$$

\section{What We Have Learnt from $\mathrm{CO}_{2}$ Sequestration in Saline Aquifers}

$\mathrm{CO}_{2}$ emission reduction becomes one of the main concerns of the world; hence deep saline aquifers can be used as $\mathrm{CO}_{2}$ storage [18] to decrease $\mathrm{CO}_{2}$ emission. Aquifers are the favorable storage places comparing to depleted reservoirs and coal seams, mainly because of safety issues [19] [20]. Poorly-sealed abounded wells are reducing the safety of storage capability of depleted reservoirs, while water-bearing permeable rock nature of saline aquifers is increasing the safety factor [21].

To perform a successful $\mathrm{CO}_{2}$ sequestration project in saline aquifers, monitoring and verification of storing process is a must. Underground distribution of $\mathrm{CO}_{2}$ needs to be monitored during the life of project. It is essential to identify when the minimum volume and saturation of $\mathrm{CO}_{2}$ has been reached in the storage reservoir.

Lithology, geomechanics and geology of the storage reservoir is main elements which drive $\mathrm{CO}_{2}$ detection capability within the reservoir. Having said that, it must also be noted that all of these reservoir characteristics have some level of uncertainties. There is no doubt about that these uncertainties may have an impact on $\mathrm{CO}_{2}$ distribution detection in the reservoir. Therefore, these uncertainty elements also need to be taken into account for the $\mathrm{CO}_{2}$ sequestration and $\mathrm{CO}_{2}$ distribution detection planning stages [22].

$\mathrm{CO}_{2}$ detectability also relies on the phase in which $\mathrm{CO}_{2}$ is injected in the storage reservoir. $\mathrm{CO}_{2}$ is customarily injected as a liquid form to be able to transform to a supercritical phase. Supercritical state has both a liquid and a gas characteristic; hence supercritical fluid expands like a gas, while keeping its density as a liquid level. $\mathrm{CO}_{2}$ density is adequate to fill the pores at depths lower than $2600 \mathrm{ft}$.

State of $\mathrm{CO}_{2}$, and the environment into which it is sequestered, have a significant bearing on the detectability of $\mathrm{CO}_{2}$. Typically, $\mathrm{CO}_{2}$ is injected as a liquid which transforms to a supercritical fluid [23]. In this state, it has properties of both a liquid and a gas so that it expands like a gas, but with a density of a liquid. At depths below $800 \mathrm{~m}, \mathrm{CO}_{2}$ density is high enough to allow efficient filling of pore space. There is also a reduction in the buoyancy difference between the $\mathrm{CO}_{2}$ and other pore fluids. 
Miscibility is another important characteristic which varies with $\mathrm{CO}_{2}$ sequestration conditions. As it is a known fact that $\mathrm{CO}_{2}$ and natural gas are miscible, therefore $\mathrm{CO}_{2}$ is able to relocate water in the pores. However, since our interest here is $\mathrm{CO}_{2}$ sequestration in saline aquifers, multiphase relationship of $\mathrm{CO}_{2}$ and the aquifer dictates the pore space volume which can be filled by $\mathrm{CO}_{2}$ [23] [24].

\section{5. $\mathrm{CO}_{2}$ Sequestration Capacity of Shale}

Coming from the extremely tight and low permeability nature of shale reservoirs, to produce from or to inject any fluid into shale reservoirs is tough. However, technological improvements in hydraulic fracturing technique made these reservoirs producible. Hydraulic fracturing basically opens artificial flow channels for reservoir fluid to flow with cracking the formation via pumping of highly pressurized fluid into the formation. Once these shale reservoirs depleted, existing fractures in the reservoir could be storage for $\mathrm{CO}_{2}$ sequestration. Another advantage of shale reservoirs is that they do not require capital expense cost such as new well drilling which is the case for saline aquifers [25].

Viability of $\mathrm{CO}_{2}$ storage in shale reservoirs can be predicted by reservoir models, since it is critical to identify $\mathrm{CO}_{2}$ storage capacity of the reservoir. There are two major criteria while performing feasibility study for $\mathrm{CO}_{2}$ sequestration in shale formations. The first criterion is the diffusivity which gives an idea about formation deliverability. The first criterion in this regard is gas adsorption/desorption characteristics of shale formations. It is an ongoing study and many researchers claim that $\mathrm{CO}_{2}$ may adsorb the shale formation more favorable than methane.

Storage capacity of shale formations for $\mathrm{CO}_{2}$ storage is promising. It is also claimed that $\mathrm{CO}_{2}$ injection time in shale reservoirs would be much faster than the methane production from these reservoirs. In addition, it is estimated that around 14.5 billion tons of $\mathrm{CO}_{2}$ can be sequestrated into shale formations in the next two decades. The estimated capacity is almost half of the U.S. $\mathrm{CO}_{2}$ emissions from power plants within the next 20 years, which is equal to $20 \%$ of total expected $\mathrm{CO}_{2}$ emission of the U.S.

Based on numerical investigation, it concluded that the maximum $\mathrm{CO}_{2}$ storage capacity for eastern U.S [24] shale gas is 1.12 million metric tons per square kilometer, and the sorbed $\mathrm{CO}_{2}$ storage capacity is estimated to be 0.72 million metric tons per square kilometer. The total $\mathrm{CO}_{2}$ storage capacity of organic-rich shales at supercritical conditions as a function of pore pressure was measured by [26] by considering the pore compressibility and sorption effects. The results state that kerogen, the organic part of the shale, acts as a molecular sieve and accounts for the gas sorption on shales. The sorption capacity of shales is affected by its TOC content, clay minerals and micropore structure. There is a large body of literature investigating the sorption capacity [27].

\section{6. $\mathrm{CO}_{2}$ Trapping Mechanisms}

Trapping mechanisms are important in $\mathrm{CO}_{2}$ sequestration feasibility studies. Four trapping mechanisms are present to our knowledge which are given in Figure 3, and can be named as: mineral trapping, solubility trapping, residual $\mathrm{CO}_{2}$ trapping, and structural/stratigraphic trapping. Trapping time is considered up to ten thousand years same as the nuclear storage projects. To give an idea about 10,000 years consideration time, it has been 11,000 years up to today since the last ice age [28].

The most common type of trapping mechanisms is geological structures for $\mathrm{CO}_{2}$ storage in depleted reservoirs. Deep saline aquifers also have structural trapping mechanism coming from their depositional environment. When upward migration of $\mathrm{CO}_{2}$ is blocked by impermeable rock layer, $\mathrm{CO}_{2}$ is trapped due to buoyancy effect.

Moving from geological structures for trapping, solubility type of trapping takes place when $\mathrm{CO}_{2}$ dissolved in formation water [28]. Reservoir pore pressure and temperature, along with the formation water salinity are the key elements for solubility trapping. $\mathrm{CO}_{2}$ solubility rises with increasing pressure, on the other hand decreases with increasing temperature and salinity. With this mechanism $\mathrm{CO}_{2}$ is trapped as a liquid phase sinking under the gas phase due to gravitational forces. Solubility type of trapping is secure and favorable for $\mathrm{CO}_{2}$ storage [29].

All in all, $\mathrm{CO}_{2}$ sequestration feasibility studies are not depending on one unique trapping mechanism. It is concluded that different geophysical characterizations will be necessary throughout the life of the project. For instance, earlier and later stages of the sequestration project might be sensitive to different characteristics, hence it is suggested that time lapse surveys must be performed through the life of the project to confirm sequestrated $\mathrm{CO}_{2}$ is trapped securely [17] [30]. 


\section{Active Carbon Capture and Sequestration (CCS) Projects Worldwide}

Carbon Capture and Sequestration projects are mainly performed in the U.S. and Europe, pie chart distribution of the world CCS projects is given in Figure 4. Canada, Australia and New Zealand, and China are also other major players of CCS projects [31]-[33].

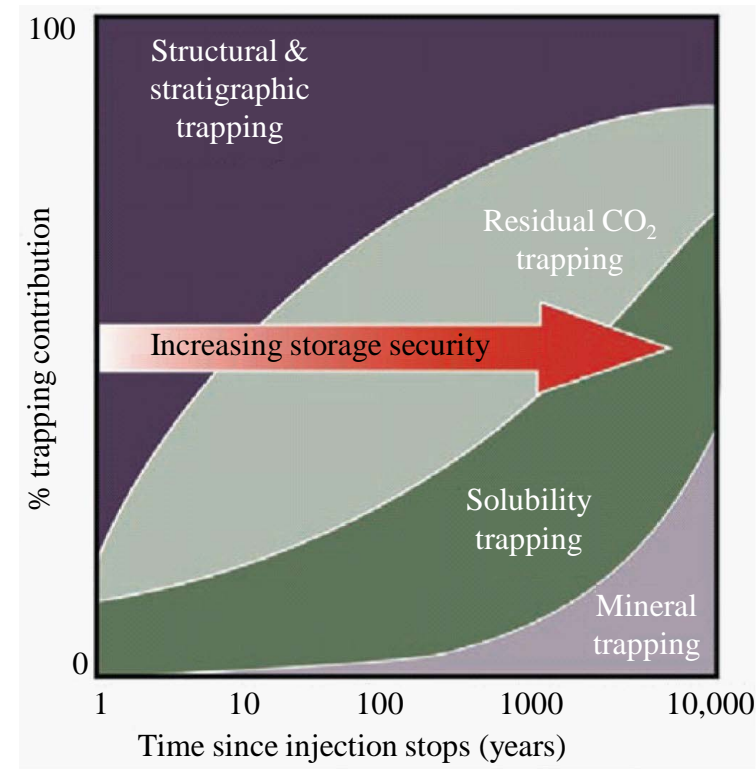

Figure 3. Schematic representation of the security of $\mathrm{CO}_{2}$ trapping mechanisms over time.

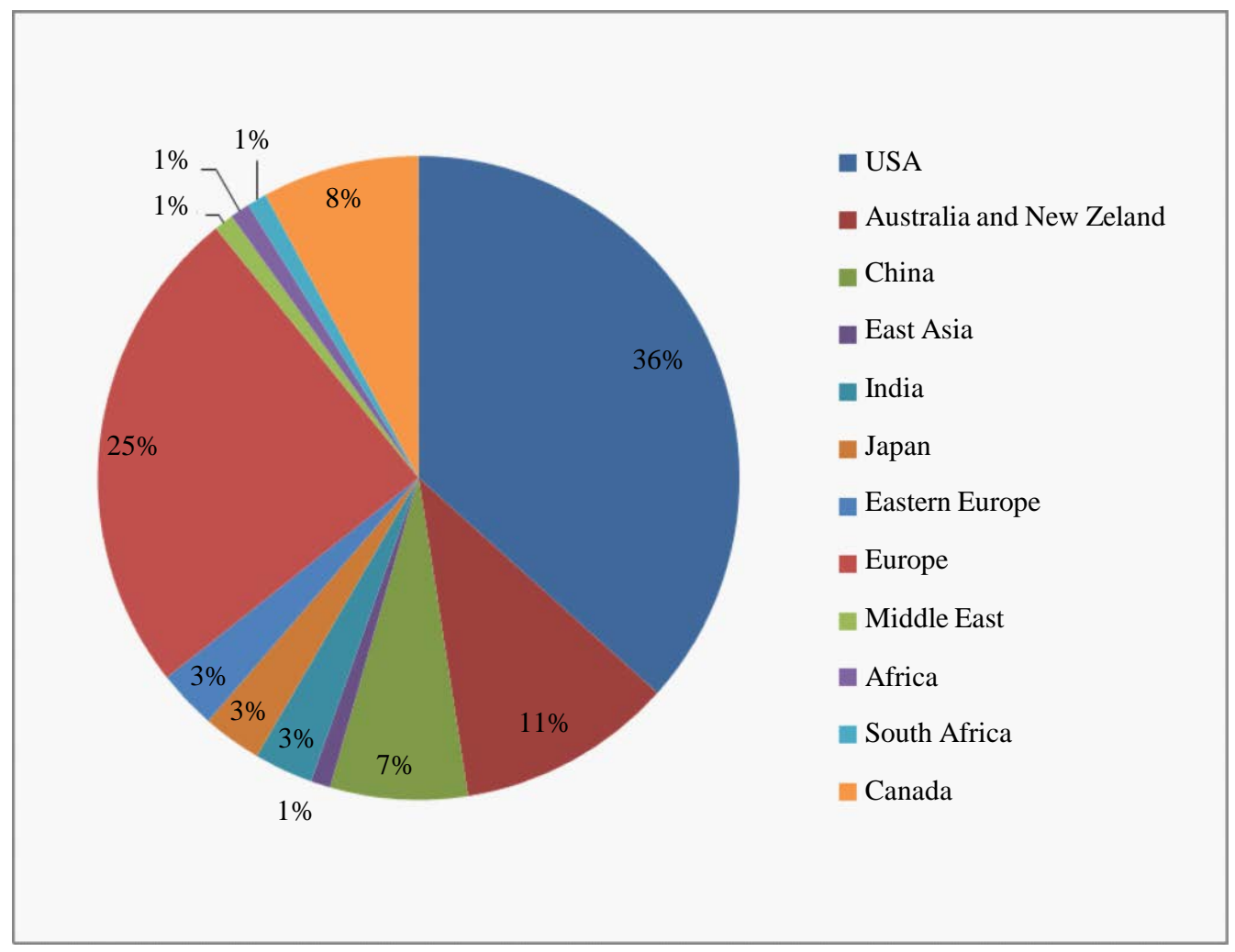

Figure 4. Countries with active CCS program. 


\section{Conclusions}

Unconventional shale reservoirs are main hydrocarbon resources of today's world, they are developed for oil and gas production. However, depleted unconventional shale reservoirs can be good candidates for $\mathrm{CO}_{2}$ sequestration and storage operations. Extremely low permeability nature of shale reservoir might seem like their lack, but on the other hand decent amount of $\mathrm{CO}_{2}$ can absorb on shale fracture surfaces. Existing natural and hydraulic fracture networks in shale reservoirs made these reservoirs attractive to permanent $\mathrm{CO}_{2}$ storage projects. That being said, when it comes to reservoir modeling for $\mathrm{CO}_{2}$ storage, many characteristic factors need to be taken into account such as buoyancy, heterogeneity of shale reservoirs, and the existence of formation water, because they will directly affect the storage capacity of the particular reservoir.

In conclusion, our extended literature review shows that shale reservoirs are good candidates for $\mathrm{CO}_{2}$ storage with the capacity of 5 to $10 \mathrm{~kg} / \mathrm{t}$ per formation. These results verify the feasibility of $\mathrm{CO}_{2}$ sequestration in shale reservoirs. It can be stated that the long term feasibility of $\mathrm{CO}_{2}$ storage in shale reservoirs needs to be extended. However, the information available to our knowledge manifests that shale reservoirs can be good storage candidates for permanent $\mathrm{CO}_{2}$ storage, therefore studies need to be focused on to make these projects practical. It is concluded that unconventional shale reservoirs have many favorable characteristics for $\mathrm{CO}_{2}$ storage, and it is expected that these reservoirs will become very attractive for $\mathrm{CO}_{2}$ sequestration projects all around the world in the very near future.

\section{References}

[1] National Energy Technology Laboratory (2010) Carbon Sequestration Atlas of the United States and Canada. 3rd Edition, the U.S. Department of Energy, Washington DC, p162. 2.

[2] Li, Z.W., Dong, M.Z., Li, S.L. and Huang, S. (2006) $\mathrm{CO}_{2}$ Sequestration in Depleted Oil and Gas Reservoirs-Caprock Characterization and Storage Capacity. Energy Conversion and Management, 47, 1372-1382. http://dx.doi.org/10.1016/j.enconman.2005.08.023

[3] Rice University, News and Media Relations (2011) Shale Gas and U. S. National Security. Rice University News and Media Relations Team, Huston.

[4] Brown, M.L. (2009) Analytical Trilinear Pressure Transient Model for Multiply Fractured Horizontal Wells in Tight Shale Reservors. M.Sc. Thesis, Colorado School of Mines, Golden.

[5] Aybar, U., Eshkalak, M.O., Sepehrnoori, K. and Patzek, T.W. (2014) The Effect of Natural Fracture’s Closure on Long-Term Gas Production from Unconventional Resources. Journal of Natural Gas Science and Engineering, 21, 1205-1231. http://dx.doi.org/10.1016/j.jngse.2014.09.030

[6] Esmaili, S., Kalantari-Dahaghi, A. and Mohaghegh, S.D. (2012) Forecasting, Sensitivity and Economic Analysis of Hydrocarbon Production from Shale Plays Using Artificial Intelligence \& Data Mining. SPE Canadian Unconventional Resources Conference, Calgary, 30 October-1 November 2012, SPE162700.

[7] Kalantari-Dahaghi, A. and Mohaghegh, S.D. (2011) Numerical Simulation and Multiple Realizations for Sensitivity Study of Shale Gas Reservoirs. SPE Production and Operations Symposium, Oklahoma City, 27-29 March 2011, SPE 141058.

[8] Carslaw, H.S. and Jaeger, J.C. (1959) Conduction of Heat in Solids. 2nd Edition, Clarendon Press, Oxford.

[9] Van Everdingen, A.F. and Hurst, W. (1949) The Application of the Laplace Transformation to Flow Problems in Reservoirs. Journal of Petroleum Technology, 1, 305-324. http://dx.doi.org/10.2118/949305-G

[10] Aybar, U., Eshkalak, M.O., Sepehrnoori, K. and Patzek, T.W. (2014) Long Term Effect of Natural Fractures Closure on Gas Production from Unconventional Reservoirs. SPE Eastern Regional Meeting, Charleston, 21-23 October 2014, SPE 171010.

[11] Ozkan, E., Raghavan, R.S. and Apaydin, O.G. (2010) Modeling of Fluid Transfer from Shale Matrix to Fracture Network. SPE Annual Technical Conference and Exhibition, Florence, 19-22 September 2010, SPE 134830.

[12] Torcuk, M.A., Kurtoglu, B., Fakcharoenphol, P. and Kazemi, H. (2013) Theory and Application of Pressure and Rate Transient Analysis in Unconventional Reservoirs. SPE Annual Technical Conference and Exhibition, New Orleans, 30 September-2 October 2013, SPE 166147.

[13] Eshkalak, M.O., Mohaghegh, S.D. and Esmaili, S. (2014) Geomechanical Properties of Unconventional Shale Reservoirs. Journal of Petroleum Engineering, 2014, Article ID: 961641.

[14] Eshkalak, M.O., Mohaghegh, S.D. and Esmaili, S. (2013) Synthetic, Geomechanical Logs for Marcellus Shale. Digital Energy Conference and Exhibition, The Woodlands, 5-7 March 2013, SPE 163690. 
[15] OmidvarEshkalak, M. (2013) Synthetic Geomechanical Logs and Distributions for Marcellus Shale. MSc Thesis, West Virginia University, Morgantown.

[16] Michael, K., Arnot, M., Cook, P., Ennis-King, J., Funnell, R., Kaldi, J., Kirste, D. and Paterson, L. (2009) CO $_{2}$ Storage in Saline Aquifers I-Current State of Scientific Knowledge. Energy Procedia, 1, 3197-3204. http://dx.doi.org/10.1016/j.egypro.2009.02.103

[17] Aybar, U., Yu, W., Eshkalak, M., Sepehrnoori, K. and Patzek, T. (2015) Evaluation of Production Losses from Unconventional Shale Reservoirs. Journal of Natural Gas Science and Engineering, 23, 509-516. http://dx.doi.org/10.1016/j.jngse.2015.02.030

[18] JafarGandomi, A. and Curtis, A. (2011) Detectability of Petrophysical Properties of Subsurface $\mathrm{CO}_{2}$-Saturated Aquifer Reservoirs Using Surface Geophysical Methods. The Leading Edge, 30, 1112-1121.

[19] Eshkalak, M.O., Aybar, U. and Sepehrnoori, K. (2014) An Integrated Reservoir Model for Unconventional Resources, Coupling Pressure Dependent Phenomena. Eastern Regional Meeting, Charleston, 21-23 October 2014, SPE 171008.

[20] White, D. and Johnson, J. (2009) Integrated Geophysical and Geochemical Research Programs of the IEA GHG Weyburn-Midale $\mathrm{CO}_{2}$ Monitoring and Storage Project. Energy Procedia, 1, 2349-2356. http://dx.doi.org/10.1016/j.egypro.2009.01.305

[21] Gale, J. and Freund, P. (2001) Coal-Bed Methane Enhancement with $\mathrm{CO}_{2}$ Sequestration Worldwide Potential. Environmental Geosciences, 8, 210-217. http://dx.doi.org/10.1046/j.1526-0984.2001.008003210.x

[22] Benson, S., Hoversten, G.M., Gasperikova, E. and Haines, M. (2004) Monitoring Protocols and Life-Cycle Costs for Geologic Storage of Carbon Dioxide. Proceedings of the 7th International Conference on Greenhouse Gas Control Technologies, Vancouver, 5-9 September 2004, 1259-1264.

[23] Benson, S. and Cole, D.R. (2008) $\mathrm{CO}_{2}$ Sequestration in Deep Sedimentary Formations. Elements, 4, 325-331. http://dx.doi.org/10.2113/gselements.4.5.325

[24] Eshkalak, M.O., Aybar, U. and Sepehrnoori, K. (2014) An Economic Evaluation on the Re-Fracturing Treatment of the US Shale Gas Resources. Eastern Regional Meeting, Charleston, 21-23 October 2014, SPE 171009.

[25] Bear, J. (1972) Dynamics of Fluids in Porus Media. Elsevier, Amsterdam.

[26] Godec, M., Koperna, G., Petrusak, R. and Oudinot, A. (2013) Potential for Enhanced Gas Recovery and $\mathrm{CO}_{2}$ Storage in the Marcellus Shale in the Eastern United States. International Journal of Coal Geology, 118, 95-104. http://dx.doi.org/10.1016/j.coal.2013.05.007

[27] Kang, S.M., Fathi, E., Ambrose, R., Akkutlu, I. and Sigal, R. (2011) Carbon Dioxide Storage Capacity of Organic-Rich Shales. SPE Journal, 16, 842-855. http://dx.doi.org/10.2118/134583-PA

[28] Eshkalak, M.O., Al-Shalabi, E.W., Sanaei, A., Aybar, U. and Sepehrnoori, K. (2014) Simulation Study on the $\mathrm{CO}_{2-}$ Driven Enhanced Gas Recovery with Sequestration versus the Re-Fracturing Treatment of Horizontal Wells in the U.S. Unconventional Shale Reservoirs. Journal of Natural Gas Science and Engineering, 21, 1015-1024. http://dx.doi.org/10.1016/j.jngse.2014.10.013

[29] Eshkalak, M.O., Al-Shalabi, E.W., Sanaei, A., Aybar, U. and Sepehrnoori, K. (2014) Enhanced Gas Recovery by $\mathrm{CO}_{2}$ Sequestration versus Re-Fracturing Treatment in Unconventional Shale Gas Reservoirs. Abu Dhabi International Petroleum and Exhibition and Conference, Abu Dhabi, 10-13 November 2014, SPE 172083.

[30] Aybar, U. (2014) Investigation of Analytical Models Incorporating Geomechanical Effects on Production Performance of Hydraulically and Naturally Fractured Unconventional Reservoirs. MSc Thesis, The University of Texas at Austin, Austin.

[31] Gensterblum, Y., Busch, A. and Krooss, B.M. (2014) Molecular Concept and Experimental Evidence of Competitive Adsorption of $\mathrm{H}_{2} \mathrm{O}, \mathrm{CO}_{2}$ and $\mathrm{CH}_{4}$ on Organic Material. Fuel, 115, 581-588. http://dx.doi.org/10.1016/j.fuel.2013.07.014

[32] Polson, D., Curtis, A. and Vivalda, C. (2012) The Evolving Perception of Risk during Reservoir Evaluation Projects for Geological Storage of $\mathrm{CO}_{2}$. International Journal of Greenhouse Gas Control, 9, 10-23. http://dx.doi.org/10.1016/j.ijggc.2012.02.010

[33] Eke, P.E., Naylor, M., Haszeldine, S. and Curtis, A. (2011) $\mathrm{CO}_{2}$-Brine Surface Dissolution and Injection: $\mathrm{CO}_{2}$ Storage Enhancement. SPE Projects, Facilities and Construction, 6, 41-53. http://dx.doi.org/10.2118/124711-PA 